\section{The development of a tool to monitor integrated care for childhood overweight and obesity in the Netherlands}

Monitoring integrated childhood obesity care

\author{
Leandra Koetsier
}

Department of Health Sciences, Faculty of Science, Vrije Universiteit Amsterdam, Amsterdam Public Health Research Institute, Amsterdam, The Netherlands

Monique Jacobs

GGD Hart voor Brabant, s-Hertogenbosch, The Netherlands

Jutka Halberstadt

Department of Health Sciences, Faculty of Science, Amsterdam Public Health Research Institute, Vrije Universiteit Amsterdam, Amsterdam, The Netherlands

Marian Sijben

Sijben Advies, Veghel, The Netherlands, and

Nick Zonneveld and Mirella Minkman

Vilans National Centre of Expertise in Long-Term Care,

Utrecht, The Netherlands and

TIAS School for Business and Society, Tilburg University, Tilburg, The Netherlands

\begin{abstract}
Purpose - The development of a national model has led municipalities in the Netherlands to implement integrated care for childhood overweight and obesity. To monitor how this approach is being implemented
\end{abstract}

(C) Leandra Koetsier, Monique Jacobs, Jutka Halberstadt, Marian Sijben, Nick Zonneveld and Mirella Minkman. Published by Emerald Publishing Limited. This article is published under the Creative Commons Attribution (CC BY 4.0) licence. Anyone may reproduce, distribute, translate and create derivative works of this article (for both commercial and non-commercial purposes), subject to full attribution to the original publication and authors. The full terms of this licence may be seen at http:// creativecommons.org/licences/by/4.0/legalcode

This study was also made possible by the contribution of the project leaders from the participating municipalities, who were kind enough to participate in this research. Besides this study was made possible by the contributions of drs. Judith Stroo, she played an important role in the adaptation process of the developed tool.

Funding: This project was carried out as part of the project Care for Obesity, which was funded by the Dutch Ministry of Health, Welfare and Sport (grant number 324043, 328544, 329657). The funder did not have any role in the study design, data collection and analysis, decision to publish, or preparation of the manuscript. This study was a collaboration with Care for Obesity (Vrije Universiteit Amsterdam) and Vilans, National Center of Excellence in Long-term Care (Utrecht).

Authors contributions: All authors made substantial contributions to the conception and design of the study, as well as playing an important role in interpreting the results. All authors were involved in providing critical feedback and revising the manuscript for important intellectual content. All authors read and approved the final manuscript.

Competing Interests: The authors have declared that no competing interests exist. 
JICA

29,2

locally, an appropriate tool is required. This study presents a "Tool to monitor the local implementation of Integrated Care for Childhood Overweight and obesity" (TICCO).

Design/methodology/approach - A three-step study was conducted in order to adapt and refine a generic integrated care questionnaire into a tool that suits the specific characteristics and context of integrated care for childhood overweight and obesity. The three consecutive steps comprised the following: a focus group session that assessed the relevance and comprehensiveness of the original integrated care instrument; a pilot questionnaire for end users that evaluated the feasibility of the preliminary tool and a pilot questionnaire that determined the feasibility and potential limitations of this adapted tool.

Findings - The adaptation process resulted in a 47-element digital tool for professionals actively involved in providing integrated care for childhood overweight and obesity. The results highlighted differences pertaining to how individual respondents judged each of the elements. These variations were found across both municipalities and different domains of integrated care.

Originality/value - This article presents an adapted tool that seeks to both support local discussion in the interpretation of individual TICCO scores and identify potential areas for improvement in local integrated care for childhood overweight and obesity.

Keywords Monitoring, Integrated care, Childhood overweight and obesity, Self-assessment tool Paper type Research paper

\section{Introduction}

The number of adults and children with overweight and obesity is increasing worldwide (Abarca-Gómez et al., 2017; The GBD 2015 Obesity Collaborators, 2017; Ng et al., 2014). In the Netherlands, in 2019, 35.4\% of Dutch adults 18 years and older had overweight, while an additional $14.7 \%$ had obesity. With regard to Dutch children aged between 4 and 18 years, $11.0 \%$ had overweight and $2.1 \%$ had obesity (CBS and RIVM, 2019a, b). Overweight, and especially obesity, can detrimentally impact upon people's physical health and psychosocial functioning. For example, there is an increased risk of both type 2 diabetes mellitus and hypertension (Skinner et al., 2015), allied with a host of psychosocial problems, including low self-esteem, depression and feelings of loneliness (Tsiros et al., 2009). Adequate support and care is required for children with overweight, and especially obesity, to help them make sustainable changes in their lifestyle that will improve their health, societal participation and quality of life, both in the short and long term (Sijben et al., 2018).

In the Netherlands, the requisite support and care for childhood overweight and obesity involves a range of different actions and actors. Its funding is based on various items of legislation. The funding of essential medical care is covered by the Health Insurance Act, while the funding of prevention, support and care for children (aged 0-18) is largely the responsibility of municipalities (Sijben et al., 2018).

In 2010, the first national integrated healthcare standard for the management of obesity in the Netherlands was published (Seidell et al., 2012). This health care standard was based on the first evidence-based multidisciplinary national guideline for the diagnosis and treatment of obesity that was published in 2008 (Seidell et al., 2008). To facilitate the implementation of this health care standard, eight Dutch municipalities (Almere, Amsterdam, Arnhem, 'sHertogenbosch, Maastricht, Oss, Smallingerland and Zaanstad) were chosen to participate in a project. To represent the variety of municipalities in the Netherlands, these eight were selected based on a variety in: the number of inhabitants, the prevalence of overweight and obesity, the prevalence of complex health care problems, region of the country, health care insurance company involved and the organization and availability of support and health care for childhood overweight and obesity. In addition the selected municipalities needed to have the local commitment of key partners and an at least partly organized system of universal and selective prevention for the integrated care (which is indicated and care related prevention) to be embedded in. The project sought to improve the standards of support and care for children with overweight and obesity and subsequently led to the development of the "National model for integrated care for childhood overweight and obesity" (Sijben et al., 2018). This model is 
predicated on both scientific and practice-based evidence and utilizes a processual approach to provide integrated care for children with overweight and obesity, aged $0-19$ years. The model functions as a guidebook for implementing integrated care within local municipalities and comprises four components: "Vision" (a broad perspective); "Process" (a specific, clear, six-step trajectory); "Partners" (collaboration between professionals operating within the health and social care domain); and "Finance" (arranging funding within the existing financial system). Implementing the "National model for integrated care for childhood overweight and obesity" across 35 Dutch municipalities by 2020 has been designated as a key ambition of Dutch policymakers. The long-term goal is to implement it across all municipalities in the Netherlands by 2030.

In order to optimize stepwise local implementation, it is essential to closely monitor the process, while, simultaneously, effectively acquiring practice-based knowledge. Consequently, there was an exigent need to develop a tailor-made instrument to monitor the implementation of integrated care for children with overweight and obesity. In recent years, several models have been developed to provide insights into the dimensions and activities that constitute integrated care and collaborative processes, such as the chronic care model (Wagner et al., 2001) and the rainbow model of integrated care (RMIC) (Valentijn et al., 2015a; Valentijn et al., 2015b). However, these models do not present activities and conditions required for high-quality integrated care. In this respect, the development model for integrated care (DMIC) proposed by Minkman (Minkman, 2012) represents a more promising model for monitoring the development of integrated care, insofar as it, firstly, comprises generic ingredients that are used in multiple contexts and countries, and, secondly, delineates how to measure and monitor these aspects of integrated care. Moreover, the DMIC has been found to be a validated instrument for monitoring the implementation of integrated care (Longpré and Dubois, 2015; van Duijn et al., 2018). For these reasons, it was deemed to be a potentially appropriate tool for monitoring the implementation of integrated care for our specific target group: children with overweight and obesity.

The DMIC was developed through a systematic approach, which consisted of carrying out a literature review, a three-round Delphi study and multiple validation studies (Minkman, 2012). The model describes the essential activities associated with integrated care from a generic perspective, rather than being disease-specific or client group-specific. It describes four developmental phases of integrated care in which these aforesaid activities take place, as follows: the initiative and design phase, the experimental and execution phase; the expansion and monitoring phase and the consolidation and transformation phase. The model comprises 89 elements that are considered of critical relevance to the development of integrated care (for instance: "the functioning of the integrated care is monitored" or "professionals are aware of each other's expertise and tasks"). Elements are grouped into nine domains, which are labelled as follows: "Quality care", "Performance management", "Inter-professional teamwork", "Delivery system", "Roles and tasks", "Client-centeredness', "Commitment", "Transparent entrepreneurship" and "Result-focused learning" (see Figure 1. The Development Model of Integrated Care) (Minkman, 2012). The DMIC has been validated within 84 integrated care services in both the Netherlands and Canada, including for stroke, acute myocardial infarct (AMI) and dementia patients (Longpré and Dubois, 2015; Minkman, 2012; Minkman et al., 2011, 2013; Zonneveld et al., 2017). Moreover, the model has been shown to be effective for quality management purposes, supporting the further development of integrated care practices (Vat et al., 2016; Zonneveld et al., 2017).

While the DMIC has ably proven its value as a generic integrated care instrument for a broad range of client groups, ultimately the project leaders in the eight participating municipalities, who were coordinating the implementation of integrated care for childhood overweight and obesity deemed the 89-elements DMIC to be too extensive (i.e. time consuming), partially inapplicable, overlapping or too complex for their specific purposes.

\section{Monitoring integrated childhood obesity care}


JICA

29,2

102
Figure 1.

The development model of integrated care - (Minkman, 2012)

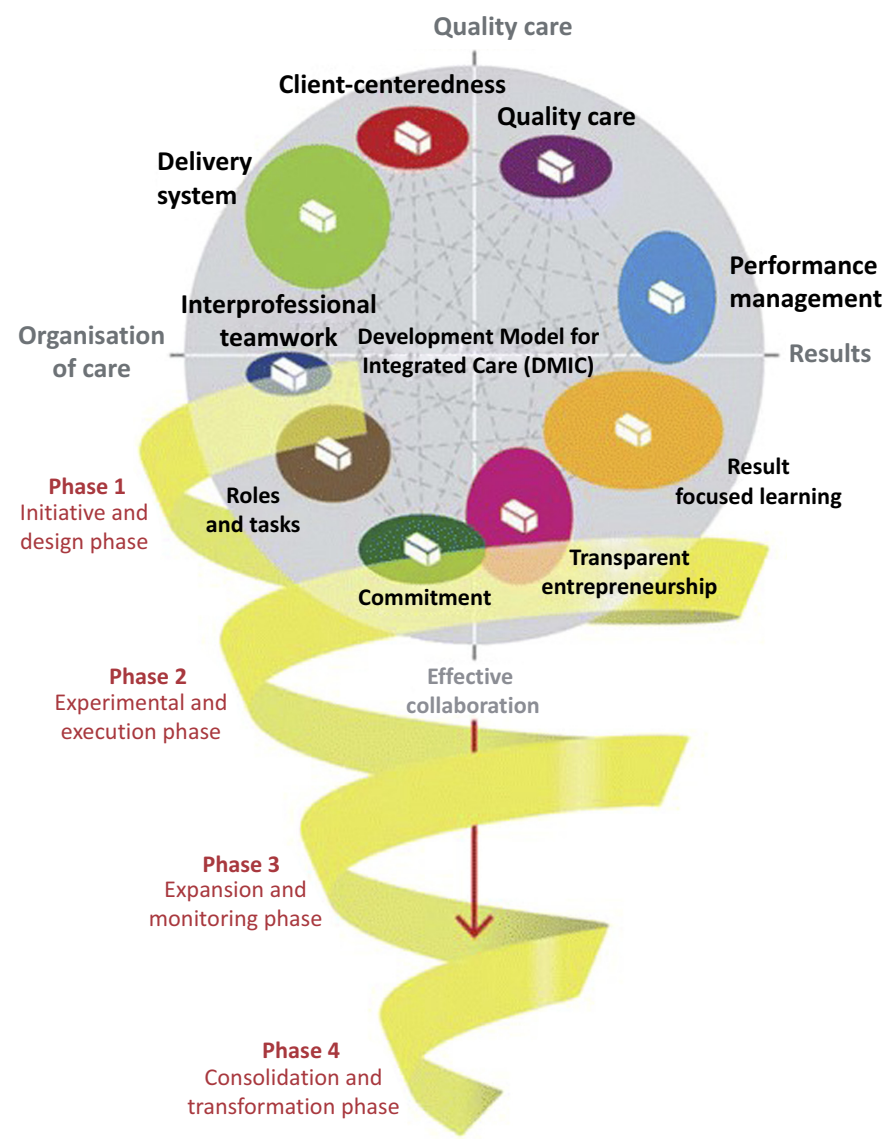

Consequently, the present study aims to address these aforesaid limitations of the DMIC and adapt it to develop a new tool through which to monitor the local implementation of integrated care for childhood overweight and obesity.

\section{Research methodology}

Study design and setting

In order to tailor the DMIC to the specific context of childhood overweight and obesity, a tripartite process was conducted over the course of a two-year period (2017-2018). A multidisciplinary research team was established, comprising experts specialized in integrated care, development models of integrated care and childhood overweight and obesity. Eighteen project leaders from the participating municipalities (ranging from one to three for each municipality) were also involved in the adaptation process. Their role of project leader was to coordinate the local implementation of the integrated care for childhood overweight and obesity. The project leaders involved had a professional background in health care policy, health promotion or (youth) health care. The majority of municipalities employed two project leaders to secure the project-based knowledge as well as substantial knowledge related to the support and care for children with overweight or obesity. Some project leaders combined their coordinating role with the provision of support and care for 
children with overweight or obesity. The study population comprised project leaders as well as other network partners involved in the participating municipalities (mostly professionals involved in the project organization).

\section{Study procedure}

Step 1: focus group. In order to assess the relevance and comprehensiveness of the DMIC, a pre-existing shorter version was used, which comprised the top ten elements related to and representative of each developmental phase, as assessed by Minkman (Minkman et al., 2009a, 2009b). This version with 38 unique elements (two elements occur in two phases), which is characterized by the original nine domains and four developmental phases, was adapted in accordance with the professional terminology used in the "National model for integrated care for childhood overweight and obesity", before subsequently being presented to the project leaders.

The relevance and comprehensiveness of the elements that make up the 38-element DMIC were assessed via a focus group session with the project leaders. First, the clarity and relevance of each element was individually assessed by the participants. Second, the participants assessed the comprehensiveness of the remaining elements and provided suggestions for additional elements they felt were currently missing, which directly informed our second step (see Figure 2. Adaptation process and routing of elements).

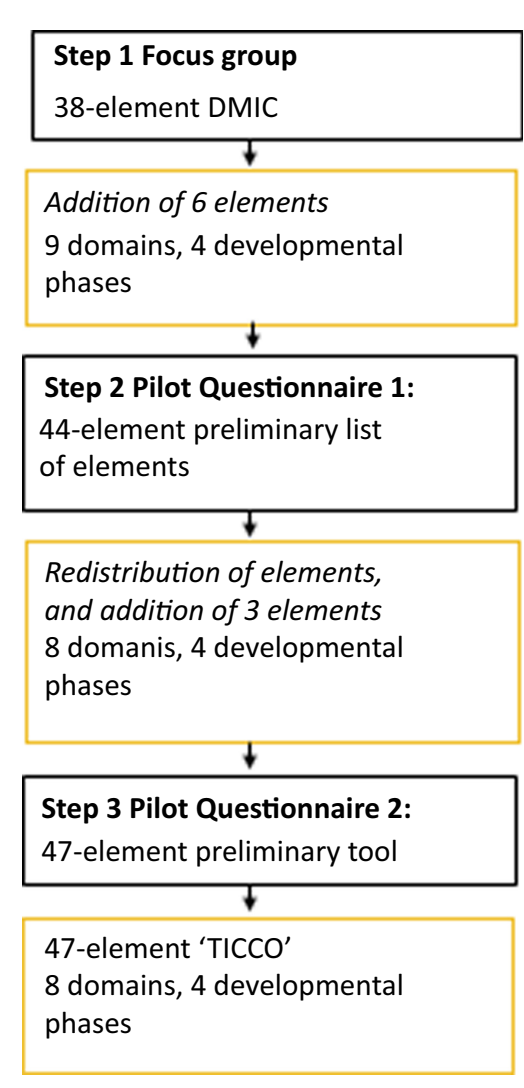

Monitoring integrated childhood obesity care
Figure 2. Adaptation process and routing of elements 
JICA

29,2

104

Step 2: pilot questionnaire (1). The aim of step 2 was to evaluate the feasibility of the preliminary list of elements developed in step 1. Project leaders invited professionals currently involved in providing integrated care to complete the 44-element online questionnaire (using Qualtrics). The 44 elements were formulated as statements. The answer scale ranged from 1 "totally disagree' to 5 "totally agree". Professionals were also asked to assess the questionnaire and provide feedback at the end of the questionnaire.

Subsequently, the research team discussed the outcomes, feedback and experiences. Regarding the feasibility, elements of domains with less than five elements were redistributed. Alongside this, each new element was then assigned to one of the four development phases (see Figure 2. Adaptation process and routing of elements).

Step 3: pilot questionnaire (2). Step 3 was conducted to assess both the feasibility and some of the potential limitations of the preliminary tool. At least two professionals (in addition to the project leader) were asked to complete the online questionnaire in Qualtrics. These professionals were only invited to participate in the pilot if they were sufficiently involved in the local realization of integrated care, at both the organizational and operational level, in their municipality for at least six months.

The 47 elements were formulated as statements. In response to the slight variation in element scores found in step 2 (pilot questionnaire 1), the scale of the statements in this third step (pilot questionnaire 2) was extended from 1 "totally disagree" to 10 "totally agree", to assess whether this would result in greater variation in the element scores. In this step, the options to answer "do not know" and "cannot assess properly" were added (see Figure 2. Adaptation process and routing of elements).

\section{Findings}

Step 1: focus group

During the focus group session with the project leaders, four elements that were deemed to be "not clear" were subsequently reformulated, while the four that they considered to be "not relevant" were, ultimately, omitted. Concerning the comprehensiveness of the questionnaire, three additional themes were suggested to be included in the instrument, as follows: (1) a shared vision of integrated care for childhood overweight and obesity; (2) collaboration between professionals in the health care and social care domain and (3) shared responsibility for the functioning of the integrated care. For these respective themes, ten additional elements were developed by the research team and added to the questionnaire.

Since four elements were omitted and ten elements were added, this focus group session thus resulted in a preliminary 44-element list of elements, categorized into the nine domains and four developmental phases and specifically adapted to monitor the local implementation of integrated care for children with overweight and obesity (see Figure 2. Adaptation process and routing of elements).

\section{Step 2: pilot questionnaire (1)}

To evaluate the feasibility of the preliminary list of elements, the 44-element online questionnaire was completed by 58 respondents (response rate: 81,6\%). The number of respondents for each municipality varied from 0 (in one municipality) to 14 . Overall scores for the domains ranged from 3.3 to 3.9 (on a scale from 1 to 5). Overall scores for the developmental phases were 3.9 (phase 1), 3.6 (phase 2), 3.6 (phase 3) and 3.3 (phase 4). The results show a slight variation in element scores between municipalities (see Table 1. Domain scores and developmental phases step 2 Pilot Questionnaire (1)).

Of the 58 respondents, 27 of them filled in one or more of the feedback questions. There were no specific comments on the formulation of the elements. With respect to content and 


\begin{tabular}{|c|c|c|c|}
\hline Domains & $N$ & $\begin{array}{l}\text { Step 2. Pilot questionnaire (1) (scale 1-5) } \\
\text { Overall mean and range in the means for each } \\
\text { municipality }\end{array}$ & $\begin{array}{l}\text { Monitoring } \\
\text { integrated } \\
\text { childhood }\end{array}$ \\
\hline Commitment & 63 & $3.9(3.4-4.1)$ & obesity care \\
\hline Roles and tasks & 62 & $3.5(3.3-3.7)$ & \\
\hline Inter-professional teamwork & 61 & $3.9(3.6-4.2)$ & \\
\hline Client centeredness & 60 & $3.9(3.6-4.3)$ & 105 \\
\hline Delivery system & 60 & $3.3(3.1-3.6)$ & \\
\hline Quality of support and care & 59 & $3.6(3.3-3.8)$ & \\
\hline Result-focussed learning & 59 & $3.5(2.9-3.7)$ & \\
\hline Performance management & 57 & $3.4(3.0-3.9)$ & \\
\hline Transparent entrepreneurship & 59 & $3.3(2.9-3.6)$ & \\
\hline Developmental phase 1 the initiative and design phase & 59 & $3.9(3.4-4.1)$ & Table 1. \\
\hline $\begin{array}{l}\text { Developmental phase } 2 \text { the experimental and } \\
\text { execution phase }\end{array}$ & 59 & $3.6(3.4-3.8)$ & $\begin{array}{r}\text { developmental phases } \\
\text { step } 2 \text { pilot }\end{array}$ \\
\hline $\begin{array}{l}\text { Developmental phase } 3 \text { the expansion and monitoring } \\
\text { phase }\end{array}$ & 57 & $3.6(3.4-3.9)$ & $\begin{array}{r}\text { questionnaire (1) } \\
\text { (overall mean and }\end{array}$ \\
\hline $\begin{array}{l}\text { Developmental phase } 4 \text { the consolidation and } \\
\text { transformation phase }\end{array}$ & 57 & $3.3(3.2-3.6)$ & $\begin{array}{l}\text { range in the means for } \\
\text { each municipality) }\end{array}$ \\
\hline
\end{tabular}

difficulty, around half of the participants indicated that some elements (especially those pertaining to monitoring, organization and financing) were hard to judge because the participants were not sufficiently informed about all local steps and activities. Five participants suggested adding the option to answer: "do not know", while two participants proposed that they should complete the questionnaire again in six months to assess their progress.

For the purposes of usability, elements of the domain "Roles and tasks" were redistributed since less than five elements were left in that category. Moreover, to better fit in with the professional terminology used in the "National model for integrated care for childhood overweight and obesity", two domains were renamed (the domain "Performance management" was renamed "Monitoring", while the domain "Transparent entrepreneurship" was renamed "Organization and financing"). As a result, the research team discerned that specific elements related to "Client centeredness" and "Monitoring" were missing, and, hence, decided to add three further elements (one element to "Client centeredness" and two elements to "Monitoring"). In addition to this, there was also a consensus amongst the research team that 12 elements needed to be assigned to another developmental phase. These adaptations resulted in the 47element preliminary tool that monitors the local implementation of integrated care for childhood overweight and obesity within eight domains and four developmental phases (see Figure 2. Adaptation process and routing of elements).

\section{Step 3: pilot questionnaire (2)}

The 47 elements were completed by 28 respondents from eight municipalities. The overall scores for each domain ranged from 6.1 to 7.9 (on a scale from 1 to 10). The results demonstrate higher overall scores for developmental phases 1 and 2 (7.6 and 7.3, respectively) and lower scores for developmental phases 3 and 4 (6.3 and 5.6, respectively) (see Table 2. Domain scores and developmental phases step 3 Pilot Questionnaire (2)). For some elements, individual scores ranged from 2 to 9 or 1 to 10. These variations were found across both municipalities and different domains. The results of the pilot test also highlighted variations in individual scores for professionals working in the same municipality.

The adapted instrument was named: "Tool to monitor the local implementation of Integrated Care for Childhood Overweight and obesity" (TICCO) (see Figure 2. Adaptation 


$N$

Inter-professional teamwork

\section{6}

Client centeredness

Delivery system

Quality of support and care

Result-focused learning

Monitoring

Table 2.

Domain scores and developmental phases step 3 pilot questionnaire (2) (overall mean and range in the means for each municipality)
Organization and financing

Developmental phase 1 the initiative and design phase

Developmental phase 2 the experimental and

execution phase

Developmental phase 3 the expansion and monitoring phase

Developmental phase 4 the consolidation and transformation phase municipality

$7.7(6.4-8.6)$

$7.9(7.3-9.1))$

$7.9(7.3-9.1)$

$7.2(6.7-8.3)$

$6.1(4.9-7.5)$

$6.1(5.5-8.1)$

$6.1(5.2-7.8)$

$6.3(4.5-7.5)$

$7.6(6.3-8.2)$

$7.3(6.4-8.8)$

$6.3(5.6-7.8)$

$5.6(5.2-7.4)$

process and routing of elements) "https://beta.vu.nl/nl/onderzoek/care-for-obesity/publicaties/ index.aspx\#tools"

\section{Discussion}

\section{Study findings and reflection}

The aim of this study was to develop a practical tool to monitor the local implementation of integrated care for overweight and obesity. The top 10 DMIC elements that were most relevant for each of the four developmental phases of the validated DMIC instrument served as a starting point in the development of the adapted model (Minkman, 2012). During the adaptation process, nine elements were added, elements of the domain "Roles and tasks" were redistributed among the other domains, 12 elements of the preliminary tool were assigned to another developmental phase, while the terminology was adapted to be consistent with that used in the "National model for integrated care for childhood overweight and obesity' (Sijben et al., 2018). These adjustments resulted in the 47-element digital questionnaire for professionals actively involved in the integrated care for childhood overweight and obesity: the "Tool to monitor the local Implementation of Integrated Care for Childhood Overweight and obesity" (TICCO).

Project leaders noticed that specific topics were missing in the short version of the questionnaire, and thus elements relating to a "shared vision" were added to ensure that the specific needs of the target group were met: children with overweight and obesity. Moreover, it is important to have the same goals and ambitions as included in the DMIC, and a shared vision has been found to be an essential component of success in integrated care (Kaehne, 2019; van Koperen et al., 2018).

Besides, project leaders indicated the necessity to add other elements they deemed to be of critical importance to cross-sectoral integrated care (namely, "collaboration between the health care domain and social care domain"). Due to the complexity of factors involved in overweight and obesity, professionals face the considerable challenge of having to connect the medical, social and public domain (Sijben et al., 2018). A published report from one of the participating Dutch municipalities outlined the necessity to identify the key constitutive elements of an integrated approach to providing care for children with overweight and obesity. Similarly, this report also confirms that collaboration is one of the integral elements in an integrated approach for children with overweight and obesity, which emphasizes the 
necessity for effective cooperation between different (public and private) organizations (van Koperen et al., 2018). Resultantly, the elements that have been added to make this questionnaire appropriate for the target group might also be relevant additions to short versions of the original DMIC instrument.

In the adaptation process, the feasibility of the TICCO was assessed by a multidisciplinary group of respondents. The results of the pilot questionnaires displayed variations in individual scores across both municipalities and different domains, and even within professionals working in the same municipality. These differences in individual judgement of elements between the respondents and within municipalities were greater than anticipated and are indicative of a marked discrepancy in how professionals score specific elements of the local development of integrated care within their municipality. In other words, even professionals that were employed in the same municipality had different views about their local integrated care. One potential explanation for this is that this study comprised professionals from multiple disciplines and a range of different roles. Hence, it is not altogether surprising that they may interpret and judge the elements from their distinct perspectives. Indeed, previous studies that utilized DMIC as a framework for assessing Dutch diabetes disease management also found significant differences between stakeholder groups, such as between coordinators and professionals (van Duijn et al., 2018; Vat et al., 2016; Zonneveld et al., 2017).

Furthermore, collaboration between professionals is essential, inasmuch as a sound collaborative structure has been shown to strengthen integrated care for childhood overweight and obesity (D'Amour et al., 2005; Minkman, 2012; van Koperen et al., 2018). Of course, inter-professional collaboration is a notoriously challenging and dynamic process. In this respect, several skills are prerequisites for fruitful collaboration, while maximum effort is required from all the professionals involved (D'Amour et al., 2005; D'amour et al., 2008). This study has demonstrated that large variations exist in professionals' perspectives regarding the local implementation of integrated care for children with overweight and obesity. Given that such variations in judgements are common in integrative care, it is critically important to be able to identify these distinct perspectives of different professionals and make them explicit. In so doing, professionals and others have the opportunity to reflect upon them and explore avenues to either integrate or align these perspectives in future collaborations (Breton et al., 2019).

\section{Practical implications}

Our study resulted in a practical-based tool for municipalities seeking to monitor the implementation of tailor-made integrated care for children with overweight and obesity. The importance of discussing the different perspectives of professionals and finding ways to align them is a key implication for practice. The TICCO can be used to explore both convergences and divergences in perspectives of the professionals involved in the project organization. Consequently, the TICCO is an expedient tool both for supporting local discussions on the interpretation of individual TICCO scores and for identifying areas for improvement in local integrated care, rather than being a rigorously validated measurement tool. Gaining better insight into professionals' judgement and views through using the TICCO may help to improve the implementation of local integrated care for children with overweight and obesity. Ultimately, TICCO is intended to improve this support and care through establishing better quality control and proposing targeted improvements. A further recommendation is that the individual scores must be related to professionals' positions in order to improve the meaning of the scores, which, in turn, enriches the quality of the local discussion.

It is interesting to note that the DMIC is used in Dutch integrated care settings (such as palliative care and diabetes care), as well as in other countries like Canada (Longpré and
Monitoring integrated childhood obesity care 
JICA

29,2

Dubois, 2015; Minkman, 2012; Minkman et al., 2011, 2013; Zonneveld et al., 2017). The generic DMIC instrument (short version) has proven to be an effective basis from which to develop both TICCO and the local implementation process of integrated care for childhood overweight and obesity. The process of adapting an existing generic integrated care monitoring instrument into a tailored tool can therefore be an interesting and useful strategy in all kinds of settings and countries. Moreover, as TICCO is a tailor-made instrument for the context of overweight and obesity, TICCO can with only minor adaptations be a potentially appropriate tool in other Western countries or local settings (for instance adult obesity).

\section{Limitations and suggestions for further research}

The present study is not without its limitations. Firstly, TICCO can be used as a local evaluation and discussion tool, and TICCO has underwent the first and necessary practical validation for its purpose. However, more rigorous validation studies for further development and refinement of TICCO are recommended. Due to the observed variation in absolute scores of the responding professionals, it is hard to draw conclusions about the level of local implementation. Secondly, the third step of the adaptation process comprised exactly the same group of professionals who took part in the second step, which means that a limited number of participants were involved in the study. Finally, only well-informed professionals closely involved in local integrated care were involved in the third step which explains the lower response rate, and, as such, the perspectives of a diversity of other professionals were not taken into account. However, these limitations constitute sufficient reasons for carrying out further research that uses TICCO as a local evaluation and discussion tool. For example, it would be interesting to investigate the benefits of using TICCO in every day practice. For instance, how the results are used, which actions are adopted based on the local discussions and if there are any further recommendations about the most optimal use of TICCO.

Moreover, the TICCO tool appears to be most suitable for those operating in a central position within integrated care practice, such as coordinating professionals and project leaders. For local executive professionals (such as a youth health care nurses or general practitioners), perhaps a more practical tool would be more feasible. During the development of our tool, we found that executive professionals were less informed about the implementation of integrated care and instead mainly focussed on their own contribution to the integrated care setting.

\section{Conclusion}

To ensure the smooth local implementation of integrated care for childhood overweight and obesity, it is essential to monitor the implementation process. The present study adapted the DMIC into a practical-based tool for municipalities to monitor the local implementation of integrated care for childhood overweight and obesity, which we designated as TICCO. The results from the pilot study with the preliminary tool showed individual differences in element scores within municipalities. Local discussion on the interpretation of individual TICCO scores could raise multiple opportunities for the further development of these local approaches. Therefore, the TICCO is considered to be an appropriate practice-based local evaluation and discussion tool for individual TICCO scores, rather than being a rigorously validated measurement tool to monitor the local implementation of integrated care for childhood overweight and obesity.

\section{References}

Abarca-Gómez, L., Abdeen, Z.A., Hamid, Z.A., Abu-Rmeileh, N.M., Acosta-Cazares, B., Acuin, C., Adams, R.J., Aekplakorn, W., Afsana, K. and Aguilar-Salinas, C.A. (2017), "Worldwide trends in 
body-mass index, underweight, overweight, and obesity from 1975 to 2016: a pooled analysis of 2416 population-based measurement studies in 128. 9 million children, adolescents, and adults", The Lancet, Vol. 390 No. 10113, pp. 2627-2642.

Breton, M., Wankah, P., Guillette, M., Couturier, Y., Belzile, L., Gagnon, D. and Denis, J.-L. (2019), "Multiple perspectives analysis of the implementation of an integrated care model for older adults in Quebec", International Journal of Integrated Care, Vol. 19 No. 4, p. 6.

CBS and RIVM (2019a), "Cijfers en Context. Trends" [Numbers and context. Trends], available at: https://www.volksgezondheidenzorg.info/onderwerp/overgewicht/cijfers-context/trends (accessed 15 May 2020).

CBS and RIVM (2019b), "Overgewicht. Cijfers and context. Huidige situatie" [overweight, numbers and context. Current sitiation], available at: https://www.volksgezondheidenzorg.info/ onderwerp/overgewicht/cijfers-context/huidige-situatie (accessed 15 May 2020).

D’Amour, D., Ferrada-Videla, M., San Martin Rodriguez, L. and Beaulieu, M.-D. (2005), "The conceptual basis for interprofessional collaboration: core concepts and theoretical frameworks", Journal of Interprofessional Care, Vol. 19 sup1, pp. 116-131.

D’amour, D., Goulet, L., Labadie, J.F., San Martín-Rodriguez, L. and Pineault, R. (2008), “A model and typology of collaboration between professionals in healthcare organizations", BMC Health Services Research, Vol. 8 No. 1, p. 188.

Kaehne, A. (2019), "Sharing a vision. Do participants in integrated care programmes have the same goals and objectives?", Health Services Management Research, Vol. 33 No. 3, pp. 122-129, 0951484819871136.

Longpré, C. and Dubois, C.-A. (2015), "Implementation of integrated services networks in Quebec and nursing practice transformation: convergence or divergence?", BMC Health Services Research, Vol. 15 No. 1, p. 84.

Minkman, M., Ahaus, K., Fabbricotti, I., Nabitz, U. and Huijsman, R. (2009a), "A quality management model for integrated care: results of a Delphi and concept mapping study", International Journal for Quality in Health Care, Vol. 21 No. 1, pp. 66-75.

Minkman, M.M., Ahaus, K.T. and Huijsman, R. (2009b), "A four phase development model for integrated care services in The Netherlands", BMC Health Services Research, Vol. 9 No. 1, p. 42 .

Minkman, M.M., Vermeulen, R.P., Ahaus, K.T. and Huijsman, R. (2011), "The implementation of integrated care: the empirical validation of the Development Model for Integrated Care", BMC Health Services Research, Vol. 11 No. 1, p. 177.

Minkman, M.M., Vermeulen, R.P., Ahaus, K.T. and Huijsman, R. (2013), “A survey study to validate a four phases development model for integrated care in The Netherlands", BMC Health Services Research, Vol. 13 No. 1, p. 214.

Minkman, M.M. (2012), "Developing integrated care. Towards a development model for integrated care", International Journal of Integrated Care, Vol. 12, p. e197.

Ng, M., Fleming, T., Robinson, M., Thomson, B., Graetz, N., Margono, C., Mullany, E.C., Biryukov, S., Abbafati, C. and Abera, S.F. (2014), "Global, regional, and national prevalence of overweight and obesity in children and adults during 1980-2013: a systematic analysis for the Global Burden of Disease Study 2013”, The lancet, Vol. 384 No. 9945, pp. 766-781.

Seidell, J., Beer, A. and Kuijpers, T. (2008), "Richtlijn 'Diagnostiek en behandeling van obesitas bij volwassenen en kinderen", Nederlands Tijdschrift Voor Geneeskunde, Vol. 152 No. 38, pp. 2071-2076.

Seidell, J., Halberstadt, J., Noordam, H. and Niemer, S. (2012), “An integrated health care standard for the management and prevention of obesity in The Netherlands", Family Practice, Vol. 29 suppl_1, pp. i153-i156.

Sijben, M., van der Velde, M., van Mil, E., Stroo, J. and Halberstadt, J. (2018), National Model Integrated Care for Childhood Overweight and Obesity, Care for Obesity, Amsterdam, December 2018.

Monitoring integrated childhood obesity care 
JICA

29,2

Skinner, A.C., Perrin, E.M., Moss, L.A. and Skelton, J.A. (2015), "Cardiometabolic risks and severity of obesity in children and young adults", New England Journal of Medicine, Vol. 373 No. 14, pp. 1307-17.

The GBD 2015 Obesity Collaborators (2017), "Health effects of overweight and obesity in 195 countries over 25 years", New England Journal of Medicine, Vol. 377 No. 1, pp. 13-27.

Tsiros, M.D., Olds, T., Buckley, J.D., Grimshaw, P., Brennan, L., Walkley, J., Hills, A.P., Howe, P.R. and Coates, A.M. (2009), "Health-related quality of life in obese children and adolescents", International Journal of Obesity, Vol. 33 No. 4, pp. 387-400.

Valentijn, P.P., Boesveld, I.C., Van der Klauw, D.M., Ruwaard, D., Struijs, J.N., Molema, J.J., Bruijnzeels, M.A. and Vrijhoef, H.J. (2015a), "Towards a taxonomy for integrated care: a mixed-methods study", International Journal of Integrated Care, Vol. 15, p. e003.

Valentijn, P.P., Vrijhoef, H.J., Ruwaard, D., Boesveld, I., Arends, R.Y. and Bruijnzeels, M.A. (2015b), "Towards an international taxonomy of integrated primary care: a Delphi consensus approach", BMC Family Practice, Vol. 16 No. 1, p. 64.

van Duijn, S., Zonneveld, N., Lara Montero, A., Minkman, M. and Nies, H. (2018), "Service integration across sectors in europe: literature and practice", International Journal of Integrated Care, Vol. 18 No. 2, p. 6.

van Koperen, M., van Wietmarschen, M., Seidell, J. and Hageraats, R. (2018), “Amsterdamse aanpak gezond gewicht: kansrijk?”, Een zoektocht naar de werkzame elementen, available at: https:// www.nji.nl/nl/Download-NJi/Publicatie-NJi/Rapport-Amsterdamse-Aanpak-Gezond-Gewicht_ bestand.pdf (accessed 15 May 2020).

Vat, L.E., Middelkoop, I., Buijck, B.I. and Minkman, M.M. (2016), "The development of integrated stroke Care in The Netherlands a benchmark study", International Journal of Integrated Care, Vol. 16 No. 4, p. 12.

Wagner, E.H., Austin, B.T., Davis, C., Hindmarsh, M., Schaefer, J. and Bonomi, A. (2001), "Improving chronic illness care: translating evidence into action”, Health Affairs, Vol. 20 No. 6, pp. 64-78.

Zonneveld, N., Vat, L.E., Vlek, H. and Minkman, M.M. (2017), "The development of integrated diabetes care in The Netherlands: a multiplayer self-assessment analysis", BMC Health Services Research, Vol. 17 No. 1, p. 219.

\section{Corresponding author}

Leandra Koetsier can be contacted at: 1.koetsier@vu.nl

For instructions on how to order reprints of this article, please visit our website:

www.emeraldgrouppublishing.com/licensing/reprints.htm

Or contact us for further details: permissions@emeraldinsight.com 